\title{
Predictive value of synovial fluid analysis in juvenile chronic arthritis
}

\author{
L Punzi, R Ramonda, S Glorioso, F Schiavon, S Mariuz, P F Gambari
}

\begin{abstract}
To investigate the value of synovial fluid analysis in predicting the articular evolution of juvenile chronic arthritis, synovial fluid from 29 patients with oligoarticular onset juvenile chronic arthritis were examined prospectively. The patients were subsequently classified after a three year period of observation as having polyarticular (10 patients) or pauciarticular (19 patients) disease. The synovial fluid samples were analysed for total and differential white blood cell count, total protein, $\beta_{2}$ microglobulin, and total complement activity.

For comparison, synovial fluid samples from 95 patients with adult onset rheumatoid arthritis were also analysed. In patients with polyarticular disease polymorphonuclear cells and $\beta_{2}$ microglobulin concentrations were higher than in the patients with pauciarticular disease $(80(29.2) v 58.1(25.3)$, and $3.6(1.2) v$ $2.2(0.5) \mathrm{mg} / \mathrm{l}$, respectively), but there was no significant difference from the patients with rheumatoid arthritis. Synovial fluid analysis may be useful in predicting the evolution of juvenile chronic arthritis and improve definition of its subtypes.
\end{abstract}

The type of onset is probably one of the better diagnostic and prognostic clues in juvenile chronic arthritis. ${ }^{12}$ Nevertheless, the period of observation necessary to define the type of onset is not yet well established and it is still a matter of debate whether six weeks, three months, or six months ${ }^{3}$ from onset are required to define the chronic disease state. A multicentre EULAR cooperative study recently published by Prieur et $\mathrm{al}^{4}$ suggests that a six month period may be useful in defining the clinical type of onset and that some laboratory findings such as erythrocyte sedimentation rate, white blood cell and platelet counts, levels of antinuclear antibodies, rheumatoid factor, and HLA-B27 may offer additional information. Few studies ${ }^{5-7}$ have been published on the validity of synovial fluid analysis for the assessment and outcome of juvenile chronic arthritis. To investigate the importance of this we studied the predictive value of synovial fluid analysis in 29 patients with oligoarticular onset juvenile chronic arthritis classified, according to their evolution after a period of three years of observation, into polyarticular and pauciarticular subclasses.

Patients and methods

We examined the synovial fluid of 29 patients with oligoarticular onset juvenile chronic arthritis, first observed for six months. The patients were then monitored for a period of three years to define the type of juvenile chronic arthritis. Thereafter the patients were divided into two subgroups: those with polyarticular (five or more joints affected) and pauciarticular (four or fewer joints affected) disease. For comparison, we also examined the synovial fluid of 95 patients with adult onset rheumatoid arthritis. Synovial fluid was obtained in all patients with juvenile chronic arthritis by knee joint arthrocentesis six months after the onset of disease. In patients with rheumatoid arthritis synovial fluid was also obtained from the knee joint. In all patients with rheumatoid arthritis and juvenile chronic arthritis, $3 \mathrm{ml}$ of synovial fluid were treated with sodium heparin as an anticoagulant and used to determine the total and differential white blood cell count; the remaining synovial fluid was centrifuged at $1800 \mathrm{rev} / \mathrm{min}$ for 12 minutes and the supernatant was stored at $-20^{\circ} \mathrm{C}$ for up to 15 days. In these samples the following determinations were subsequently carried out: total protein concentration by the biuret method, total complement activity by Mayer's method, ${ }^{8}$ and $\beta_{2}$ microglobulin by radioimmunoassay (supplied by Pharmacia, Uppsala, Sweden). Serum samples from patients were tested for rheumatoid factor (with a nephelometric method) and for antinuclear antibodies (by indirect immunofluorescence; discernible immunofluorescence at serum dilutions of $1: 20$ or greater was considered positive). Of the 29 patients with oligoarticular onset juvenile chronic arthritis, only two serum samples were positive for antinuclear antibodies at dilutions of 1:40 and $1: 80$, respectively; these two patients developed polyarticular disease. No serum sample was positive for rheumatoid factor.

Student's $t$ test and linear regression analysis were used for statistical analysis.

\section{Results}

The table shows the results for the analysis of synovial fluid for the patients with juvenile chronic arthritis and rheumatoid arthritis and in the two subgroups with polyarticular and pauciarticular disease. The white blood cell count did not show a significant difference between patients with juvenile chronic arthritis (19.5 $\left.(19 \cdot 1) \times 10^{9} / 1\right)$ and rheumatoid arthritis $(21 \cdot 2$ $\left.(17 \cdot 4) \times 10^{9} / 1\right)$. A trend of higher white blood cell count was shown in patients with polyarticular disease $\left(24.5(18.9) \times 10^{9} / 1\right)$ compared with pauciarticular disease $\left(16.9(19 \cdot 1) \times 10^{9} / 1\right)$, 
Mean $(S D)$ results of analyses of synovial fluid from 29 patients with oligoarticular onset juvenile chronic arthritis $(\mathcal{F C A})$ subdivided, according to the evolution, into polyarticular (polyA, 10 patients) and pauciarticular (pauciA, 19 patients) disease, and in 95 patients with adult onset rheumatoid arthritis $(R A)$

\begin{tabular}{|c|c|c|c|c|c|}
\hline $\begin{array}{l}\text { Disease (no of } \\
\text { patients) }\end{array}$ & $\begin{array}{l}\text { White blood } \\
\text { cell count } \\
\left(\times 10^{4} / l\right)\end{array}$ & $\begin{array}{l}\text { Polymorphonuclear } \\
\text { cells }(\%)\end{array}$ & $\begin{array}{l}\text { Total protein } \\
(\mathrm{g} / \mathrm{l})\end{array}$ & $\begin{array}{l}\text { Total complement } \\
(U / m l)\end{array}$ & $\begin{array}{l}\text { P., microglobulin } \\
(\dot{m} g / l)\end{array}$ \\
\hline $\begin{array}{l}\text { JCA (29) } \\
\text { PolyA (10) } \\
\text { PauciA (19) } \\
\text { RA (95) }\end{array}$ & $\begin{array}{l}19 \cdot 5(19 \cdot 1) \\
24 \cdot 5(18 \cdot 9) \\
16 \cdot 9(19 \cdot 1) \\
21 \cdot 2(17 \cdot 4)\end{array}$ & $\begin{array}{l}69(24 \cdot 1) \dagger \\
80(29 \cdot 2)^{*} \\
58 \cdot 1(25 \cdot 3)^{*} \uparrow \\
84 \cdot 4(28)+5\end{array}$ & $\begin{array}{l}45(7) \\
48(7) \\
43(7) \\
44(8)\end{array}$ & $\begin{array}{l}29 \cdot 5(15 \cdot 7) \dagger \\
32 \cdot 4(15 \cdot 8) 9 \\
27 \cdot 1(16) \\
22(16 \cdot 1) \dagger 9\end{array}$ & $\begin{array}{l}2 \cdot 8(0 \cdot 8) \ddagger \\
3 \cdot 6(1 \cdot 2)^{*:} \\
2 \cdot 2(0 \cdot 5)^{:} \\
4(1 \cdot 8) \ddagger \int \delta\end{array}$ \\
\hline
\end{tabular}

Polyarticular disease $v$ pauciarticular disease: ${ }^{*} \mathbf{p}<0.05 ;{ }^{* *} \mathbf{p}<0.01$

Rheumatoid arthritis $v$ JCA: $\nmid \mathrm{p}<0.05 ; \neq \mathrm{p}<0.001$

Rheumatoid arthritis $v$ pauciarticular disease: $\oint p<0.05$; $\oint \delta p<0.001$

Rheumatoid arthritis $v$ polyarticular disease: $\eta_{\mathrm{p}}<0.05$.

although the difference was not significant. The percentage of polymorphonuclear cells was higher in patients with rheumatoid arthritis $(84.4(28) \%)$ than in all patients with juvenile chronic arthritis $(69(24.1) \%, \mathrm{p}<0.05)$ and in patients with pauciarticular disease $(58 \cdot 1$ $(25 \cdot 3) \%, \mathrm{p}<0.05)$, and in patients with polyarticular disease $(80(29 \cdot 2) \%)$ than with pauciarticular disease $(p<0.05)$. No difference in total protein concentration was found among the groups. Total complement activity was higher in patients with juvenile chronic arthritis $(29.5(15.7) \mathrm{U} / \mathrm{ml})$ than in patients with rheumatoid arthritis $(22(16 \cdot 1) \mathrm{U} / \mathrm{ml}, \mathrm{p}<0.05)$ and in patients with polyarticular disease $(32 \cdot 4$ $(15 \cdot 8) \mathrm{U} / \mathrm{ml})$ compared with patients with rheumatoid arthritis $(p<0.05)$. The values of $\beta_{2}$ microglobulin were higher in patients with rheumatoid arthritis $(4(1.8) \mathrm{mg} / \mathrm{l})$ than in patients with juvenile chronic arthritis $(2 \cdot 8(0 \cdot 8)$ $\mathrm{mg} / \mathrm{l}, \mathrm{p}<0.001$ ) and in patients with pauciarticular disease $(2.2(0.5) \mathrm{mg} / \mathrm{l}, \mathrm{p}<0.001)$. There was also a difference between patients with pauciarticular and polyarticular disease (3.6 (1.2) $\mathrm{mg} / \mathrm{l}, \mathrm{p}<0.001)$, but not between patients with polyarticular disease and rheumatoid arthritis.

Linear regression analysis was applied in all groups and subgroups comparing each white blood cell count and other parameters measured, but no significant correlation was seen.

\section{Discussion}

The follow up study showed that in 10 of 29 $(34.5 \%)$ patients with juvenile chronic arthritis with oligoarticular onset of disease, the number of joints affected changed over three years. This observation suggests that the six month observation period now used is too brief for the definition of the type of disease progression. As the principle purpose of the definition of onset is a more rational approach to treatment, a longer period of observation may compromise the validity of this intervention. In fact, in the subset of patients with polyarticular disease, as in adult rheumatoid arthritis, the course of arthritis is often progressive and intervention with remission inducing drugs may be appropriate.

Other factors may help to further characterise these patients. For this reason it is necessary to also consider the subtypes of juvenile chronic arthritis. ${ }^{2}$ Prieur et al ${ }^{4}$ suggest that the best way to define the various subgroups of juvenile chronic arthritis is to include some laboratory investigations. However, synovial fluid analysis is not considered in their laboratory evaluation, probably because the synovial fluid is not always easily obtained. Our study indicates that when the volume of synovial fluid is increased, its analysis may offer some useful aids to evaluate the progression of juvenile chronic arthritis.

Of the analyses of synovial fluid performed, not all seem to show the same predictive value. In fact, the total white blood cell count does not seem to be very useful in differentiating juvenile chronic arthritis from adult rheumatoid arthritis. Nevertheless, although not significantly, probably due to a small number of patients, we found a higher white blood cell count in patients with polyarticular disease than in those with pauciarticular or rheumatoid arthritis, or both. It has been reported ${ }^{9}$ that the total white blood cell count in the synovial fluid of patients with juvenile chronic arthritis may be among the highest found in non-infectious arthritis and, in some instances, such a finding may also be observed $^{10}$ in the oligoarticular form. This may be associated with a higher count of polymorphonuclear cells. In our experience, the percentage of polymorphonuclear cells in patients with juvenile chronic arthritis is lower than in those with rheumatoid arthritis, and in patients with polyarticular disease it is higher than in those with pauciarticular disease.

In our study the total complement levels of synovial fluid in patients with adult rheumatoid arthritis are decreased when compared with all patients with juvenile chronic arthritis and polyarticular disease. This is in agreement with previous reports ${ }^{6}$ and may reflect a higher concentration of immunocomplexes in the synovial fluid of patients with rheumatoid arthritis.

$\beta_{2}$ Microglobulin concentrations in the synovial fluid are higher in patients with rheumatoid arthritis than in those with juvenile chronic arthritis and in patients with polyarticular disease than in those with pauciarticular disease or juvenile chronic arthritis, or both. It has been shown that $\beta_{2}$ microglobulin, a low molecular weight protein homologous with the constant region of IgG polypeptide chains and part of the HLA system, ${ }^{11}$ is found in higher concentration in the synovial fluid of patients with rheumatoid arthritis compared with patients with seronegative arthritides. ${ }^{12}$ It is possible that the higher values of $\beta_{2}$ microglobulin found in the synovial fluid of patients with evolved polyarticular disease and juvenile 
chronic arthritis may reflect a rheumatoid arthritis type outcome of these patients. On the other hand, the lower values in patients with pauciarticular disease may indicate that in these patients the disease has an outcome similar to seronegative arthritides. High concentrations of $\beta_{2}$ microglobulin may also indicate an increased risk of developing amyloidosis, a serious complication of juvenile chronic arthritis, ${ }^{13}$ as it is often seen in diseases associated with chronically high concentrations of $\beta_{2}$ microglobulin. ${ }^{14}$

Unfortunately, only some of our patients have been evaluated for the HLA system. We think that an extension of the HLA study and a longer period of follow up are required to obtain more information. Our study seems to indicate, however, that when possible analysis of synovial fluid should be considered among the investigations which may contribute to a better assessment of the subtypes of juvenile chronic arthritis.

1 Ansell B M, Wood P H N. Prognosis in juvenile chronic polyarthritis. Clin Rheum Dis 1976; 2: 397-407.

2 Cassidy J T, Levinson J E, Bass J C, et al. A study of classification criteria for a diagnosis of juvenile rheumatoid arthritis. Arthritis Rheum 1986; 29: 274-81.
3 Holt P J L. The classification of juvenile chronic arthritis. Clin Exp Rheumatol 1990; 8: 331-3.

4 Prieur A M, Ansell B M, Bardfeld R, et al. Is onset type evaluated during the first 3 months of disease satisfactory for defining the sub-groups of juvenile chronic arthritis? A EULAR Cooperative Study. Clin Exp Rheumatol 1990; 8: 321-5.

5 Cassidy J T, Brody J L, Martel W. Monarticular juvenile rheumatoid arthritis. $\mathcal{F}$ Pediatr 1967; 70: 867-72.

6 Hedberg H. The total complement activity of synovial fluid in juvenile forms of arthritis. Acta Rheumatol Scand 1971 17: 279-85

7 Martin C L, Pachman L M. Synovial fluid in seronegative juvenile rheumatoid arthritis: studies of immunoglobulins, complement and $\alpha_{2}$-macroglobulin. Arthritis Rheum 1980 23: 1256-61.

8 Mayer M M, Eaton B B, Heidelberger $M$. The activating effect of magnesium and other cations on the haemolytic process function of complement. $\mathcal{F}$ Exp Med 1946; 84: 535-9.

9 Zuckner J, Baldassare A, Chang F, Auclair R. High synovia fluid leukocyte counts of non-infectious etiology. Arthritis fluid leukocyte counts of non-in

10 Hassell A, Denton J, Freemont A J, Holt P J L. Synovia fluid cytology in juvenile chronic arthritis. Br $\mathcal{F}$ Rheumato 989; 28 (suppl 2): 60

11 Grey H M, Kubo R T, Colon S M, et al. The small subunit HL-A antigen is $\beta_{2}$ microglobulin. $\mathcal{J}$ Exp Med 1973; 138 1608-12.

12 Todesco S, Punzi L, Montanaro D, Gambari P F, Borsatti A 2 microglobulin in synovial fluid of rheumatoid arthritis. Rheumatol 1980; 7: 555-8.

13 Schnitzer T J, Ansell B M. Amyloidosis in juvenile chronic polyarthritis. Arthritis Rheum 1977; 20 (suppl 2): 245-52.

14 Gejyo F, Yamada T, Odani S, et al. A new form of amyloid protein associated with chronic hemodialysis was identified 129: $701-6$. 